Farm animal welfare - who writes the rules?

Occasional Publication No. 23 - British Society of Animal Science 1999

edited by A. J. F. Russel, C. A. Morgan, C. J. Savory, M. C. Appleby and T. L. J. Lawrence

\title{
Cross-suckling in beef suckler cows with natural and adopted calves
}

\author{
H. D. Randle \\ Department of Agriculture and Food, Seale-Hayne Faculty, University of Plymouth, Newton Abbot TQ12 6NQ
}

\section{Introduction}

Interactions beyond a single-suckling beef cow and her calf are rare in the early post-partum period (Le Neindre, 1982) which would suggest that the dam-calf bond is robust. However, there is evidence that the dam-calf bond can be disrupted by both the calf and the dam. Young calves have been known to exhibit non-specific following responses to any large, moving object (KileyWorthington and de la Plain, 1983) consequently leading to disruption of the mother-young bond (Gubanick, 1981). Illman and Spinka (1983) also observed non-specific following responses made by beef calves in the early post-partum period which resulted in attempts to suck alien dams. It is not surprising therefore that cross-sucking is common under group-housing conditions. Indeed, Edwards (1983) found that in group-housed dairy cows 6\% of suckling was directed towards cows other than the natural mother (aliens) and that one-third of the calves sucked from an alien dam at some point during the first 6 days of life. Spinka and Illman (1992) successfully made use of this opportunistic tendency of calves, encouraging them to suck alien dams as their only source of milk in an extensive rearing system.

Cows do not always rear a single calf e.g. a cow may have twins and therefore rear two natural calves. Price et al. (1984) found that the bond between the dam and a twin calf was less robust than the bond between the dam and a single calf. Furthermore, cows suckling twins were generally more permissive to alien calves (calves other than their own) than cows suckling a single calf. Similarly, Kiley-Worthington (1976) found that double-suckling beef cows were also more permissive to alien calves than singlesuckling beef cows. There is also evidence that twin calves are more persistent in trying to suck alien cows than single-suckled calves (Price et al., 1984). The objectives of the work reported in this paper were first, to examine the cross-sucking activity of natural and adopted calves and secondly to compare the sucking behaviour of adoptees acting as adoptees and adoptees acting as aliens.

\section{Material and methods}

A group of 21 individuals, comprising seven trios (each consisting of a South Devon cow, her homebred natural calf and an adopted calf) were observed for a week at 5 months post adoption. Adoptions were carried out using the method developed by Kiley-Worthington (1976) (for further details see Randle (1999a)).

During the observation period all incidences of crosssuckling which occurred between 06.00 and $21.00 \mathrm{~h}$ were recorded. Observations included all of the behaviours that occurred between the dam and sucking calves (her natural, her adoptee and any others, 'aliens'). The full list of behaviours recorded during a suckling session is given in Randle (1999a). Data recorded also included the identity of the alien (the cross-sucking calf), the composition of the suckling group joined by the alien, the sucking position assumed by the alien (inside - on the inside of an already sucking calf, parallel and adjacent to the cow, or outside - on the outside of an already sucking calf or between the cow's hind legs) and the duration of sucking. The sucking positions and durations recorded for adopted calves sucking their adoptive dams were also utilized (Randle, 1999b).

At the end of the observation period the success of the seven adoptions was rated using the five-point system developed by Kiley-Worthington and de la Plain (1983). Randle (1999a) gives detailed descriptions of R (rejected), F1 (level one fostering), F2 (level two fostering), A1 (level one adoption) and A2 (level two adoption).

The proportion of cross sucking exhibited by natural and adopted calves was compared using the Fisher exact test. The proportions of successful and unsuccessful attempts made by alien calves on different types of already suckling groups were calculated. The sucking behaviour of adoptees when acting as adoptees (i.e. sucking on their adoptive dam) with that of adoptees acting as aliens (i.e. sucking on alien dams) was compared by means of two-way ANOVAs, on first, sucking position (inside versus outside) and secondly on sucking durations achieved. 


\section{Results}

By the 1st week of month 5 post adoption six of the seven adoptions were considered to be successful, i.e. the cow had adopted the second calf and no human intervention was necessary to ensure successful suckling (see Table 1, Randle (1999a)).

Of the 74 suckling sessions observed in the 1st week of month 5 post adoption $38 \quad(51 \%)$ consisted of the natural and adopted calves, 13 $(18 \%)$ consisted of only the natural calf, $10(13 \%)$ consisted of the natural and adopted calves and an alien calf and $13(18 \%)$ consisted of the natural calf and an alien calf. Within the population of seven natural calves and seven adopted calves the mean proportion of sucking of alien dams was 0.30 (s.e. 0.27). This ranged from 0 to $0 \cdot 78$. Five of the seven adopted calves engaged in cross sucking activity, i.e. acted as an alien, compared with just one of the seven natural calves. This represented a significantly greater proportion of cross-sucking in adopted calves (Fisher exact test, $P<0.05$ ). Of the 56 attempts made by alien calves to suck, $45(80 \%)$ were successful. A calf attempting to cross-suck a dam is most likely to be successful if he/she attempts to suck on a cow already nursing two calves, the natural and either the adoptee or another alien, and least likely if he/she attempts to suck a cow already nursing just her natural calf (Figure 1).

A two way ANOVA performed on the frequency of adopted calves acting as adoptees and adopted

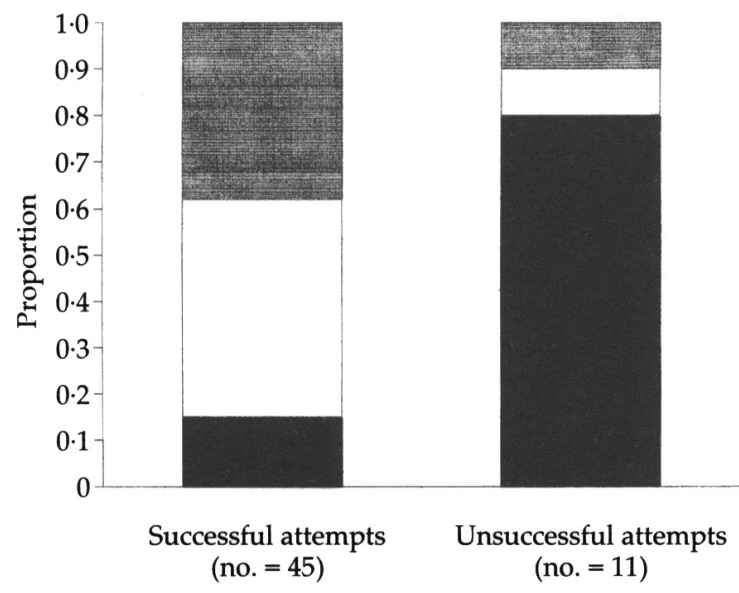

Figure 1 Proportion of successful and unsuccessful attempts made to cross-suck on dams already nursing her natural calf $(\square)$, her natural and adopted calf $(\square)$, and her natural and one other alien calf (ㅁ). calves acting as aliens, occupying the inside and outside sucking positions showed that there was no significant difference in the positions occupied by adoptees and aliens. A similar two-way ANOVA performed on the sucking durations achieved by adoptees acting as adoptees and adoptees acting as aliens demonstrated that both adoptees and aliens spent a greater proportion of time sucking from the outside positions than from the inside positions $(P<0.01)$.

\section{Discussion}

Adopted calves engaged in significantly greater levels of cross-sucking compared with natural calves. Within this system there was a relatively high proportion of cross-sucking. However this may be explained by the fact that the data were collected at 5 months post adoption. This is a time by which relations between the dam and young are weakening (Veissier et al., 1990).

There is evidence that calves which are acting as aliens in order to obtain milk from a dam other than their own (i.e. their own natural dam, or own adoptive dam) are extending the opportunistic strategy that they have developed in order to obtain milk from their adoptive dam (see Randle (1999a and b). The results obtained in this study show that the best strategy for a calf acting as an alien is to join a suckling group in which two calves (either the natural and adopted or natural and another alien calf) are already sucking. Price $e t$ al. (1984) concluded that the presence of the natural calf is very important if aliens are going to be able to suck. In their study they found that $82.9 \%$ of cross sucking occurred when the natural calf was already sucking and $5 \cdot 7 \%$ when the natural was nearby. In this study it was found that the cow did not tolerate attempts by an additional calf if just her natural calf was sucking but would if she was already nursing her natural and one other (either her adoptee or another alien calf) It appears that once the cow is nursing two calves she is generally more permissive to additional calves (a characteristic of double-suckling cows noted by Kiley-Worthington, 1976). Comparison of the sucking behaviour of adopted calves sucking their adoptive dams and sucking other dams showed that they did not alter their strategy to obtain milk since they assume similar positions (typically outside see preceding paper) and suck for similar durations.

\section{Acknowledgements}

This work was undertaken as part of a Ph.D. at the University of Exeter. Dr Kiley-Worthington and $\mathrm{Mr} \mathrm{C}$. Rendle are thanked for their help and guidance with this work. 


\section{References}

Edwards, S. A. 1983. The behaviour of dairy cows and their newborn calves in individual or group housing. Applied Animal Ethology 10: 191-198.

Gubernick, D. G. 1981. Parent and infant attachment in mammals. In Parental care in mammals (ed. D. G. Gubernick and P. H. Klopfer), pp. 117-169. Plenum Press, New York.

Illman, G. and Spinka, M. 1993. Maternal behaviour of dairy heifers and suckling of their newborn calves in group housing. Applied Animal Behaviour Science 36: 91-98.

Kiley-Worthington, M. 1976. Fostering and adoption of beef cattle. Digest - British Cattle Breeders Club 31: 42-55.

Kiley-Worthington, M. and de la Plain, S. 1983. The behaviour of beef suckler cattle (Bos taurus). Birkhauser Verlag, Basel.

Le Neindre, P. 1982. Cow-calf relationships: the effects of management type. In Welfare and husbandry of calves (ed. J. P. Signoret), pp. 5-15. Martinus Nijhoff, London.
Price, E. O., Martinez, C. L. and Coe, B. L. 1984. The effects of twinning on mother-offspring behaviour in range beef cattle. Applied Animal Behaviour Science 13: 309-320.

Randle, H. R. 1999a. Initiation of suckling in suckler cows with natural and adopted calves. In Farm animal welfare who writes the rules? (ed. A. J. F. Russel, C. A. Morgan, C. J. Savory, M. C. Appleby and T. L. J. Lawrence), pp. 116-119. British Society of Animal Science occasional publication no. 23.

Randle, H. R. 1999b. Sucking position and duration in natural and adopted calves. In Farm animal welfare - who writes the rules? (ed. A. J. F. Russel, C. A. Morgan, C. J. Savory, M. C. Appleby and T. L. J. Lawrence), pp. 119-121. British Society of Animal Science occasional publication no. 23.

Spinka, M. and Illman, G. 1992. Suckling behaviour of young dairy calves with their own and alien mothers. Applied Animal Behaviour Science 33: 165-174.

Veissier, L., Le Neindre, P. and Garel, J. P. 1990. Decrease in cow-calf attachment after weaning. Behavioural Processes 21: $95-105$. 